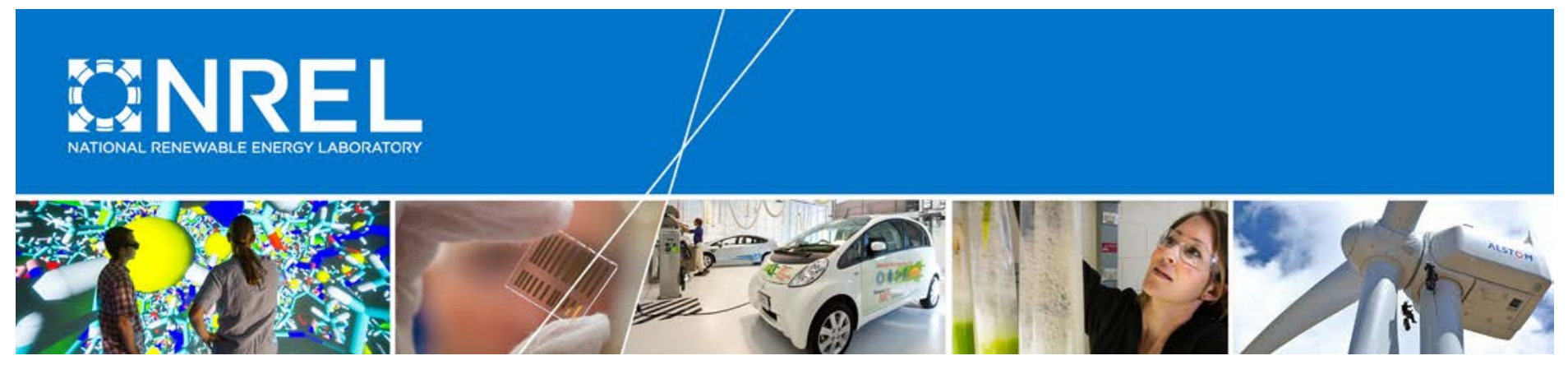

\title{
Analysis of Aurora's Performance Simulation Engine for Three Systems
}

Janine Freeman and Joe Simon National Renewable Energy Laboratory

NREL is a national laboratory of the U.S. Department of Energy Office of Energy Efficiency \& Renewable Energy Operated by the Alliance for Sustainable Energy, LLC

This report is available at no cost from the National Renewable Energy Laboratory (NREL) at www.nrel.gov/publications.

Technical Report

NREL/TP-7A40-64213

July 2015 


\section{Analysis of Aurora's Performance Simulation Engine for Three Systems}

Janine Freeman and Joe Simon National Renewable Energy Laboratory

Prepared under Task No. PV10.IN36
NREL is a national laboratory of the U.S. Department of Energy Office of Energy Efficiency \& Renewable Energy Operated by the Alliance for Sustainable Energy, LLC

This report is available at no cost from the National Renewable Energy Laboratory (NREL) at www.nrel.gov/publications.

\section{Technical Report}

NREL/TP-7A40-64213

July 2015

Contract No. DE-AC36-08GO28308
15013 Denver West Parkway

Golden, CO 80401

303-275-3000 • www.nrel.gov 


\title{
NOTICE
}

This report was prepared as an account of work sponsored by an agency of the United States government. Neither the United States government nor any agency thereof, nor any of their employees, makes any warranty, express or implied, or assumes any legal liability or responsibility for the accuracy, completeness, or usefulness of any information, apparatus, product, or process disclosed, or represents that its use would not infringe privately owned rights. Reference herein to any specific commercial product, process, or service by trade name, trademark, manufacturer, or otherwise does not necessarily constitute or imply its endorsement, recommendation, or favoring by the United States government or any agency thereof. The views and opinions of authors expressed herein do not necessarily state or reflect those of the United States government or any agency thereof.

This report is available at no cost from the National Renewable Energy Laboratory (NREL) at www.nrel.gov/publications.

Available electronically at SciTech Connect http:/www.osti.gov/scitech

Available for a processing fee to U.S. Department of Energy and its contractors, in paper, from:

\author{
U.S. Department of Energy \\ Office of Scientific and Technical Information \\ P.O. Box 62 \\ Oak Ridge, TN 37831-0062 \\ OSTI http://www.osti.gov \\ Phone: 865.576.8401 \\ Fax: 865.576.5728 \\ Email: reports@osti.gov
}

Available for sale to the public, in paper, from:

\author{
U.S. Department of Commerce \\ National Technical Information Service \\ 5301 Shawnee Road \\ Alexandra, VA 22312 \\ NTIS http://www.ntis.gov \\ Phone: 800.553 .6847 or 703.605 .6000 \\ Fax: 703.605.6900 \\ Email: orders@ntis.gov
}




\section{Acknowledgments}

The authors would like to thank the team at Aurora Solar for providing their data for analysis. In addition, the authors appreciate the support of the Department of Energy SunShot Incubator Program for making funding available to complete this analysis. 


\section{Nomenclature or List of Acronyms}

NREL

PV

RMSE
National Renewable Energy Laboratory

Photovoltaic

Root-mean-squared error 


\section{Introduction}

Aurora Solar Inc. is building a cloud-based optimization platform to automate the design, engineering, and permit generation process of solar photovoltaic (PV) installations. They requested that the National Renewable Energy Laboratory (NREL) validate the performance of the PV system performance simulation engine of Aurora Solar's solar design platform, Aurora. In previous work, NREL performed a validation of multiple other PV modeling tools [1], so this study builds upon that work by examining all of the same fixed-tilt systems with available module datasheets that NREL selected and used in the aforementioned study. Aurora Solar set up these three operating PV systems in their modeling platform using NREL-provided system specifications and concurrent weather data. NREL then verified the setup of these systems, ran the simulations, and compared the Aurora-predicted performance data to measured performance data for those three systems, as well as to performance data predicted by other PV modeling tools.

\section{Methodology}

Aurora Solar and NREL modeled three PV systems using the Aurora platform:

Table 1: Systems Modeled by Aurora Solar in Aurora

\begin{tabular}{|l|l|l|l|l|}
\hline System & Size & Type & Location & $\begin{array}{l}\text { Year } \\
\text { Modeled }\end{array}$ \\
\hline RSF1 & $385 \mathrm{~kW}$ & Fixed tilt & Golden, CO & 2011 \\
\hline RSF2 & $408 \mathrm{~kW}$ & Fixed tilt & Golden, CO & 2012 \\
\hline Visitor Parking & $524 \mathrm{~kW}$ & Fixed tilt & Golden, CO & 2012 \\
\hline
\end{tabular}

Aurora Solar used system specifications and concurrent weather data provided by NREL to model these systems; see [2] for more detailed system specifications. NREL then verified the setup of these three systems in Aurora's platform, ran the simulations within the Aurora platform, and used the resulting hourly Aurora-predicted performance data in this validation study. NREL also verified that the transposition model and module model type were consistent with the methodology of the previous validation study.

The same validation methodology that was used in [1] was applied to the current study. In summary, systems were modeled as closely as possible using high-quality measured concurrent weather data as an input. Quality-control procedures had been implemented in the previous study to remove hours affected by sensor errors, component downtime, system downtime, nighttime hours, and hours affected by snow; the same quality-controlled datasets were used in the current validation. See [1] and [2] for further methodology detail.

A crucial aspect of PV modeling is understanding the magnitude of loss assumptions that are used by a PV modeling tool to account for phenomena that are not explicitly modeled, such as soiling effects, system availability, etc. NREL used all of Aurora Solar's default loss assumptions in these simulations (which are based on the default loss factors in the PVWatts tool) except for the availability loss, which was set to $0 \%$ because we compared results to data that were quality-controlled to remove downtime. This procedure is consistent with the 
methodology used in [2] to determine loss assumptions, and it results in a total loss assumption of $10.5 \%$, compared to Aurora's usual default loss assumption of $13.2 \%$.

\section{Results}

The results from the Aurora simulations were compared to quality-controlled measured data and other PV modeling tools at both annual and hourly timescales.

\subsection{Annual}

The annual error of a PV modeling tool's prediction quantifies the over- or under-prediction of an annual energy estimate compared to measured data for that time period, normalized by the measured energy. On an annual basis, Aurora performs similarly to other tools examined in previous validation studies. Figure 1 shows Aurora's annual energy predictions, with its default loss assumption of $10.5 \%$, compared to four other tools, also using each tool's default assumptions (a table showing those default losses can be found in [1]).. Aurora compares within the same range as the other tools, showing annual error within $\pm 6 \%$ of measured data for all three systems.

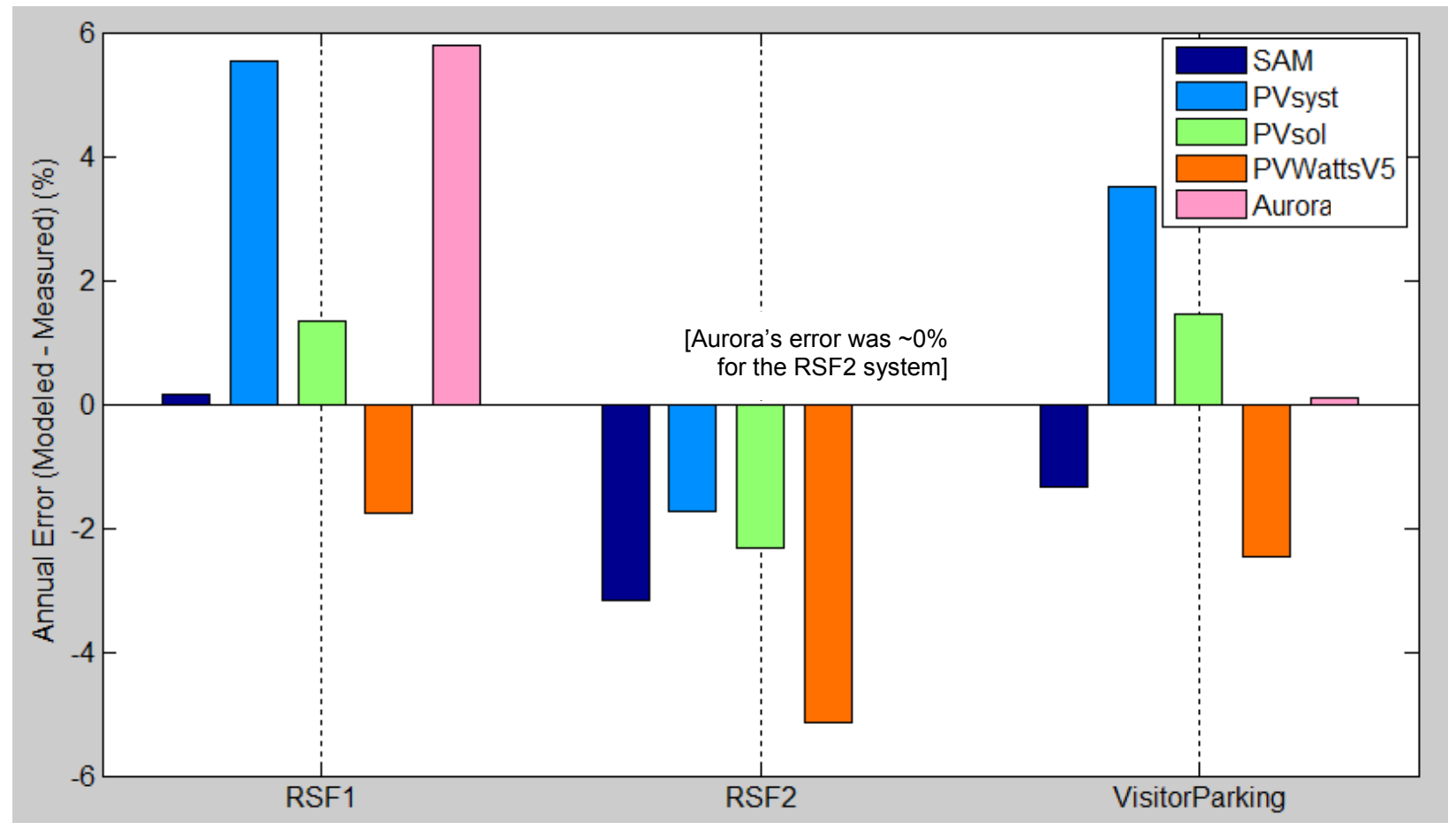

Figure 1: Annual error of tools using default loss assumptions.

\subsection{Hourly}

The normalized root-mean-squared error (RMSE) evaluates the PV modeling tool error on an hourly basis; see [2] for the definition of this metric. Aurora's hourly normalized RMSE falls within $4.5 \%$ for each of the three systems examined, which is comparable with the other tools analyzed in previous validation work using their default losses. To help demonstrate the necessity of including some form of losses, several tools were also run with the losses zeroed out. As expected, the zero-loss configurations show a higher RMSE than all of the default loss 
configurations (including Aurora) for all three systems. This result is seen because real systems do experience the losses that were zeroed out in the zero-loss configurations.

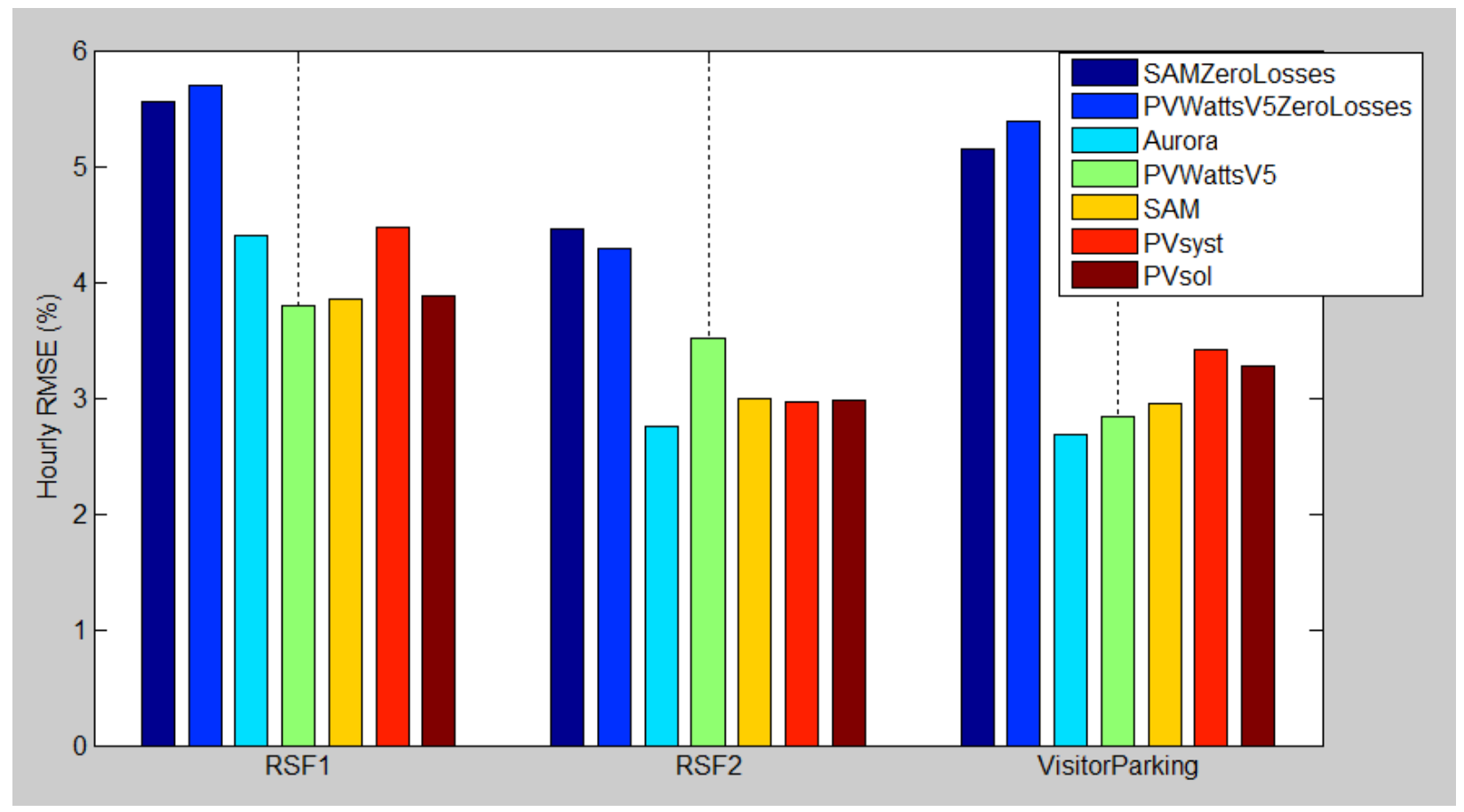

Figure 2: Hourly normalized RMSE of tools.

\section{Conclusions}

Three systems were initially modeled by Aurora Solar, and NREL subsequently verified, simulated, and analyzed the simulated performance as compared to measured data and other PV modeling tools that had been analyzed in a previous validation study. The Aurora predictions were comparable with predictions by other PV modeling tools, achieving an annual error within $\pm 6 \%$ and an hourly normalized RMSE within $4.5 \%$ for the three systems simulated. The Aurora predictions compare more closely with the default loss configurations of other tools, rather than the zero-loss configurations, which is the expected result.

Because only three systems were analyzed in this study, this serves as a good preliminary validation of the Aurora platform, but more extensive validation with additional systems and a greater variety of system locations, types, and other aspects could provide additional information about the strengths and weaknesses of this PV modeling engine. This study does not comment on the usability of the product. 


\section{References}

1. J. Freeman, J. Whitmore, L. Kaffine, N. Blair, and A.P. Dobos, "System Advisor Model: Flat Plate Photovoltaic Performance Modeling Validation Report," NREL Technical Report TP6A20-60204, December 2013.

2. J. Freeman, J. Whitmore, N. Blair, and A.P. Dobos, "Validation of multiple tools for flat plate photovoltaic modeling against measured data," $40^{\text {th }}$ IEEE Photovoltaic Specialists Conference, 2014. 